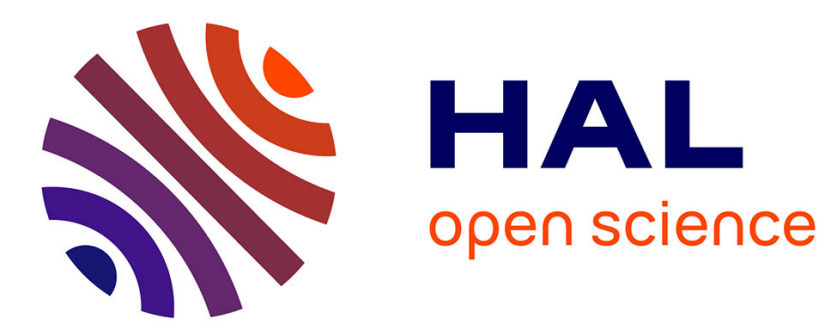

\title{
Comprehensive role of thermal combined ultrasonic pre-treatment in sewage sludge disposal
}

Hongbo Liu, Xingkang Wang, Song Qin, Wenjia Lai, Xin Yang, Suyun Xu, Eric Lichtfouse

\section{- To cite this version:}

Hongbo Liu, Xingkang Wang, Song Qin, Wenjia Lai, Xin Yang, et al.. Comprehensive role of thermal combined ultrasonic pre-treatment in sewage sludge disposal. Science of the Total Environment, 2021, 789, pp.147862. 10.1016/j.scitotenv.2021.147862 . hal-03251840

\author{
HAL Id: hal-03251840 \\ https://hal.science/hal-03251840
}

Submitted on 7 Jun 2021

HAL is a multi-disciplinary open access archive for the deposit and dissemination of scientific research documents, whether they are published or not. The documents may come from teaching and research institutions in France or abroad, or from public or private research centers.
L'archive ouverte pluridisciplinaire HAL, est destinée au dépôt et à la diffusion de documents scientifiques de niveau recherche, publiés ou non, émanant des établissements d'enseignement et de recherche français ou étrangers, des laboratoires publics ou privés. 


\title{
Comprehensive role of thermal combined ultrasonic pre-treatment in sewage sludge disposal
}

\author{
Hongbo Liu ${ }^{\mathrm{a}, *, 1}$, Xingkang Wang ${ }^{\mathrm{a}, 1}$, Song Qin ${ }^{\mathrm{a}}$, Wenjia Lai ${ }^{\mathrm{b}}$, Xin Yang ${ }^{\mathrm{a}}$, Suyun $\mathrm{Xu}^{\mathrm{a}, *}{ }^{\text {, Eric Lichtfouse }}{ }^{\mathrm{c}}$ \\ a School of Environment and Architecture, University of Shanghai for Science and Technology, 516 Jungong Road, 200093 Shanghai, China \\ ${ }^{b}$ Chongqing New World Environment Detection Technology Co.LTD, 22 Jinyudadao, 401122 Chongqing, China \\ c Aix-Marseille Univ, CNRS, IRD, INRA, Coll France, CEREGE, 13100 Aix en Provence, France
}

\section{H I G H L I G H T S}

- Combined thermal and ultrasonic pretreatment was proposed to enhance AD performance.

- The combined method significantly enhanced the dissolution of DOMs in SS.

- The combined method increased biogas production and degradation of antibiotics.

- The correlation between DOMs and the degradation of antibiotics was discussed.

- The comprehensive role of this combined method in SS disposal has been elucidated.

Editor: Huu Hao Ngo

\section{Keywords:}

Sewage sludge

Antibiotics

Thermal pre-treatment

Ultrasonic pre-treatment

Dissolved organic matters

\section{G R A P H I C A L A B S T R A C T}

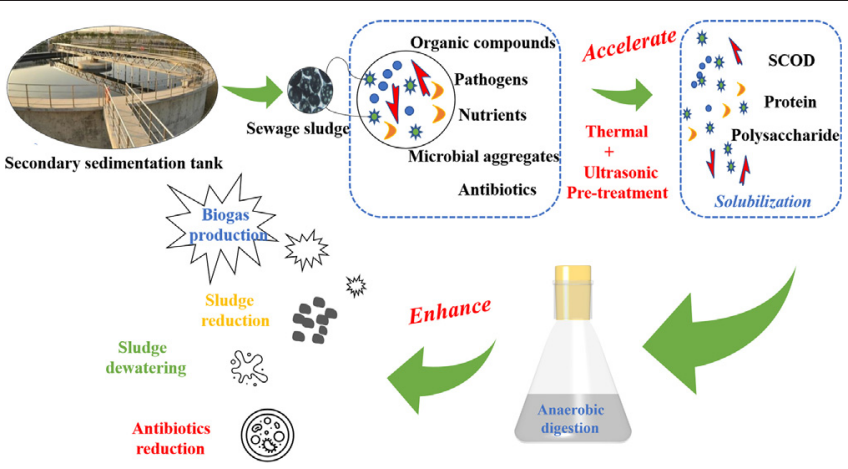

\begin{abstract}
A B S T R A C T
Thermal/ultrasonic pre-treatment of sludge has been proven to break the hydrolysis barriers of sewage sludge (SS) and improve the performance of anaerobic digestion (AD). In this study, the objective was to investigate whether the combination of two pre-treatment methods can achieve better results on the AD of SS. The results indicated that, compared with the control group and separate pre-treatment groups, the thermal combined ultrasonic pre-treatment presented more obvious solubilization of soluble proteins, polysaccharides, and other organic matters in SS. The combined method promoted the dissolution of protein-like substances more effectively, with biogas production increased by $19 \%$ and the volatile solid (VS) removal rate improved to above $50 \%$ compared with the control group. The capillary suction time is reduced by about $85 \%$, which greatly improved the dewatering performance of SS. In addition, the combined method has advantages in degrading sulfonamide antibiotics, roxithromycin and tetracycline. Particularly, by analyzing the interaction between the degradation of different antibiotics and the composition of dissolved organic matters (DOMs), it was found that the composition of DOMs could affect the degradability of different antibiotics. Among them, the high content of tyrosine-like and tryptophan-like was conducive to the degradation of sulfamethoxazole, and the high content of fulvic acid-like and humic acid-like was conducive to the degradation of roxithromycin and tetracycline. This work evaluated the comprehensive effect of thermal combined ultrasonic pre-treatment on SS disposal and provided useful information for its engineering.
\end{abstract}

Abbreviations: SS, sewage sludge; AD, anaerobic digestion; WWTPs, wastewater treatment plants; DOMs, dissolved organic matters; COD, chemical oxygen demand; SCOD, soluble

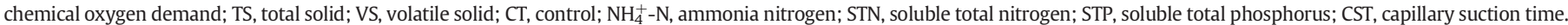
* Corresponding author at: 516, Jungong Road, 200093 Shanghai, China.

E-mail addresses: Liuhb@usst.edu.cn (H. Liu), xusy@usst.edu.cn (S.Xu).

${ }^{1}$ Hongbo Liu and Xingkang Wang contribute equally to this work. 


\section{Introduction}

Sewage sludge (SS) is the residue produced by centralized wastewater treatment plants (WWTPs) after waste treatment from various sources. Its composition of pollutants is characterized by solid and organic compounds, pathogens, microbial aggregates, filamentous bacteria, nutrients, and heavy metals (Harrison et al., 2006; Buaisha et al., 2020 ). In addition, about $70 \%$ of the undegradable antibiotics in the WWTPs are present in the digested sludge, which could be transferred to the soil and aquatic environment during disposal processes such as landfill and land use (Zhang and Li, 2018). However, management and treatment of SS are expensive and account for nearly half of the total sewage treatment cost (Khanh Nguyen et al., 2021). As a result, development and upgradation of more effective SS treatment and/or disposal technologies is in urgent need under the framework of circular economy.

Current technologies for SS disposal include anaerobic digestion (AD), dewatering, thermal drying, incineration and landfill disposal (Ding et al., 2021). Internationally, AD technology is the mainstream technology of SS disposal in EU, USA, Canada and Japan (Raheem et al., 2018). AD can not only treat organic waste including SS, but also recover energy from it, providing an environmentally friendly strategy. According to China's overall situation, "thickening-anaerobic digestiondewatering-land application" is the priority technical route of sludge treatment and disposal (Yang et al., 2015). But at present, the low hydrolysis ratio of SS has been recognized as a severe challenge to AD, which limits its application and development in WWTPs (Liao et al., 2014). Khanh Nguyen et al. pointed out that pre-treatment of SS is a prerequisite for accelerating hydrolysis and improving AD efficiency (Khanh Nguyen et al., 2021). A large number of studies have shown that pre-treatment methods including photocatalysis, thermal hydrolysis, sonication, enzymatic hydrolysis, alkaline hydrolysis, freeze-thaw and mechanical disintegration have positive effects in the AD process of SS (Scharnberg et al., 2020; Anjum et al., 2016; Memon and Memon, 2020). The main pre-treatment effects are reducing particle size, solubilization, enhancement of biodegradability, the formation of insoluble compounds, and degradation of organic substances (Carlsson et al., 2012). Thermal pre-treatment is considered as the most effective technique to improve digestibility of SS in sewage treatment plants. This is mainly reflected in the fact that thermal pre-treatment can change the rheological properties of SS, improve digestion load rate, increase biogas production, and promote biodegradability and dehydration (Barber, 2016). Kumar Biswal et al. studied the AD of low-thermal pre-treatment $\left(60-120^{\circ} \mathrm{C}\right)$ of saline waste activated sludge and found that pretreatment enhanced methane yield (13.7-29.6\%), and improved organics hydrolysis and volatile solid reduction (maximum 24.6\%) (Kumar Biswal et al., 2020). Similarly, thermal pre-treatment could reduce total solid (TS) by $54.7 \%$, volatile solid (VS) by $60.4 \%$, and the chemical oxygen demand (COD) by 59.2\% (Han et al., 2017). Thermal hydrolysis pre-treatment could also improve the dewaterability of sludge $(4.6 \pm 0.5 \%$ ) (Zhang et al., 2018). In addition, levels of antibiotics such as kanamycin, tetracycline, macrolide and lincosamide could also be reduced by thermal pre-treatments. When the thermal treatment was performed at $200{ }^{\circ} \mathrm{C}$ and $180{ }^{\circ} \mathrm{C}$ for $8 \mathrm{~h}$, antibacterial activity of Kanamycin was reduced $97.9 \%$ and $96.4 \%$ respectively (Tang et al., 2020); on the other hand, the total concentration of tetracycline, oxytetracycline, chlortetracycline and azithromycin decreased by $57.9-90.2 \%$ after thermal hydrolysis pre-treatments (Li et al., 2015; Sun et al., 2019; Tang et al., 2020; Zhang and Li, 2018).

Ultrasonic pre-treatment is another common practice for SS disposal, which could effectively destroy the bacterial cell wall of sludge (Tyagi et al., 2014). The sonication efficiency is explained by high pressure on cells, generation of free radicals such as hydroxyl radical $(\bullet \mathrm{OH})$, hydrogen radical $(\cdot \mathrm{H})$, nitrogen radical $(\cdot \mathrm{N})$ and oxygen radical $(\cdot \mathrm{O})$, and hydro-mechanical shear forces produced by ultrasonic cavitation at low frequencies (Tiehm et al., 2001). Ultrasonic could effectively accelerate hydrolysis of SS, complete disintegration of biomass within 5-10 min and improve the reduction rate of volatile solid (Nguyen et al., 2017). As a result biogas production of SS could be increased by $50 \%$ with the ultrasonic pre-treatment (Pilli et al., 2011). In addition, after the combined ultrasonic and bio-leaching treatment, the absolute abundance of 16s rRNA, sul gene, and tet gene decreased by $1.81,1.56-1.58$, and $0.34-1.23 \log$ units respectively (Huang et al., 2020).

Although both thermal pre-treatment and ultrasonic pre-treatment technologies have been confirmed improving AD performance of SS, they have basically reached the bottleneck for further improvement; the combination application of both thermal pre-treatment and ultrasonic pre-treatment could very likely produce synergistic effects breaking this barrier. Currently, there are only a few studies that combine these two pre-treatment methods (Hassan et al., 2020; Şahinkaya and Sevimli, 2013). Specifically, in the study of Hassan et al., the effects of thermal combined ultrasonic pre-treatment on the increase of methane (40.76\%), the removal rate of COD (63.06\%) and the removal rate of VS (60-66\%) were discussed. In the study of Sahinkaya \& Sevimli, the thermal combined ultrasonic pre-treatment could quickly promote the decomposition of SS, increase the methane production (13.6\%), and improve the dewaterability of SS after AD. However, the removal of antibiotics by thermal combined ultrasonic pre-treatment is rarely investigated. On the other hand, there is barely any study linking the concentration of DOMs with the degradation of antibiotics.

In this study, we analyzed and compared thermal pre-treatment, ultrasonic pre-treatment and thermal combined ultrasonic pre-treatment methods treating SS efficiently. The changing profiles of various DOMs before $\mathrm{AD}$ were firstly investigated in detail, and then the biogas production efficiency, sludge dewatering performance, and antibiotics degradation after $\mathrm{AD}$ were evaluated, the relationship between the concentration of DOMs and the degradation of antibiotics was finally analyzed.

\section{Materials and methods}

\subsection{Research plan}

The research plan of the current work entails preparation of samples, pre-treatment of SS using thermal pre-treatment, ultrasonic pretreatment, and thermal combined ultrasonic pre-treatment, the analysis of various DOMs in the SS, followed by AD of both treated and control samples of SS and their subsequent investigation. Supplementary materials Fig. 1 reflected the specific process of our work in the form of a flowchart, and the materials and test methods used in the process were expanded below.

\subsection{Sludge samples}

The SS was sampled in the secondary sedimentation tank of a sewage treatment plant in Suzhou City, placed in a sealed container, and stored at $4{ }^{\circ} \mathrm{C}$ for later use within $48 \mathrm{~h}$. The basic properties of SS under investigation were listed in Table 1.

\subsection{Pre-treatments}

We investigated the following pre-treatments of the SS in terms of the solubilization of DOMs and the reduction of ammonia nitrogen $\left(\mathrm{NH}_{4}^{+}-\mathrm{N}\right)$ : control $\left(\mathrm{CT}\right.$, without treatment); 1 h heating at $60{ }^{\circ} \mathrm{C}, 70^{\circ} \mathrm{C}$, $80{ }^{\circ} \mathrm{C}, 90^{\circ} \mathrm{C}$ or $100{ }^{\circ} \mathrm{C} ; 1 \mathrm{~h}$ sonication $1 \mathrm{~h} 40 \mathrm{kHz}(\mathrm{S}) ; 1 \mathrm{~h}$ heating at $100{ }^{\circ} \mathrm{C}$ then $1 \mathrm{~h}$ sonication at $40 \mathrm{kHz}\left(\mathrm{S} 100{ }^{\circ} \mathrm{C}\right)$. Eight replicate samples of $250 \mathrm{~mL}$ of pretreated sludge were centrifugated $10 \mathrm{~min}$ at $10,000 \mathrm{rpm}$ to separate the sludge residue from the supernatant. The supernatant was stored at $4{ }^{\circ} \mathrm{C}$ for determination of soluble protein, polysaccharide, $\mathrm{COD}$ and $\mathrm{NH}_{4}^{+}-\mathrm{N}$. 
Table 1

Characteristics of the SS under investigation.

\begin{tabular}{ll}
\hline Parameters & Value \\
\hline $\mathrm{pH}$ & $6.48 \pm 0.01$ \\
Total solids (TS, w\%) & $3.42 \pm 0.08$ \\
Volatile solids (VS, w\%) & $2.43 \pm 0.04$ \\
VS/TS (w\%) & $71.05 \pm 2.90$ \\
Total chemical oxygen demand (TCOD, mg/L) & $57,133.00 \pm 57.00$ \\
Soluble chemical oxygen demand (SCOD, mg/L) & $108.00 \pm 5.50$ \\
SCOD/TCOD (w\%) & $0.20 \pm 0.01$ \\
Ammonia nitrogen $\left(\mathrm{NH}_{4}^{+}-\mathrm{N}, \mathrm{mg} / \mathrm{L}\right)$ & $706.30 \pm 3.53$ \\
Soluble polysaccharides (SPS, mg/L) & $14.01 \pm 0.70$ \\
Soluble proteins (SPN, mg/L) & $4.80 \pm 0.24$ \\
Total nitrogen (TN, $\mathrm{mg} / \mathrm{L}$ ) & $3214.42 \pm 5.63$ \\
Total phosphorus (TP, mg/L) & $30.70 \pm 0.51$ \\
\hline
\end{tabular}

\subsection{Effect of pre-treatments on performance of $A D$}

This part explored the effects of pre-treatments on TS, VS, soluble total nitrogen (STN), and phosphorus (STP), soluble chemical oxygen demand (SCOD), capillary suction time (CST) and antibiotics of the SS. Four pre-treatment investigations were carried out: control (CT, without treatment); $1 \mathrm{~h}$ heating at $100{ }^{\circ} \mathrm{C}(\mathrm{T}) ; 1 \mathrm{~h}$ sonication $1 \mathrm{~h} 40 \mathrm{kHz}$ (S); $1 \mathrm{~h}$ heating at $100{ }^{\circ} \mathrm{C}$ then $1 \mathrm{~h}$ sonication at $40 \mathrm{kHz}\left(\mathrm{S} 100{ }^{\circ} \mathrm{C}\right)$. $150 \mathrm{~mL}$ of above SS were mixed with $50 \mathrm{~mL}$ of inoculated sludge (taken from a kitchen waste fermenter in Suzhou, which has strong biological activity and could be used to accelerate the initial stage of the biological process) in $250 \mathrm{~mL}$ serum bottles. Nitrogen gas $\left(\mathrm{N}_{2}\right)$ flush were used to remove oxygen $\left(\mathrm{O}_{2}\right)$ from SS before it was incubated for 20 days in a digital constant-temperature oscillator under the conditions of running temperature of $55^{\circ} \mathrm{C}$ and shaking speed of $120 \mathrm{rpm}$. The initial $\mathrm{pH}$ was $7.20 \pm 0.02$. The biogas produced was collected in $2 \mathrm{~L}$ airbags before analyzed. $10 \mathrm{~mL}$ samples were taken for TS, VS, and CST tests on day 3 and day 18 respectively. Samples were also centrifuged for $10 \mathrm{~min}$ at $10,000 \mathrm{rpm}$ to harvest the supernatant to analysis SCOD, STN, STP and the mud to analysis antibiotics.

\subsection{Analysis methods}

The amount of biogas was measured by a graduated syringe. $\mathrm{NH}_{4}^{+}-\mathrm{N}$, SCOD, TS, VS, TN and TP were determined with standard methods (Public and Association, 1998). Protein content in SS was determined by the Folin-phenol reagent colorimetry and polysaccharide content in SS was determined by the phenol sulfuric acid method.

According to the fluorescence area integration (FRI) method proposed by (Wen, 2003), we used a Hitachi F-7000 (Hitachi Analog Company, Japan) three-dimensional fluorescence spectrometer to measure DOMs in supernatant of the pretreated sludge. The light source is a $150 \mathrm{~W}$ excitation arc lamp, and the photomultiplier tube (photomultiplier tube, PMT) voltage is $700 \mathrm{~V}$. The excitation spectrum range is $200-500 \mathrm{~nm}$, and the scanning step length is $5 \mathrm{~nm}$; the emission spectrum range is $250-550 \mathrm{~nm}$, and the scanning speed is $12,000 \mathrm{~nm} / \mathrm{min}$. In order to calibrate the influence of instrument conditions and Raman scattering on the fluorescence spectrum, ultrapure water $(18.25 \mathrm{M} \Omega \cdot \mathrm{cm})$ was used as blank (In order to ensure that it is within the measurement range, we diluted all the samples by 500 times).

After centrifugation, the samples were filtered with a $0.45 \mu \mathrm{m}$ filter membrane. The sludge samples were taken in a material tray, prefrozen at $-20^{\circ} \mathrm{C}$ for $4-6 \mathrm{~h}$ with a freeze-drier of model SJIA-10N-50A (Shuangjia, China), then passed through an 80 -mesh sieve after grinding. We used the shaking-ultrasonic-centrifugation method to extract pollutants from solid samples: weighed $0.05 \mathrm{~g}$ sludge sample, added $7 \mathrm{~mL}$ extractant (3.5 mL methanol + 3.5 mL EDTA-Mcllvaine solution); after fully shaking, sonicated for $10 \mathrm{~min}$, then centrifuged at $4000 \mathrm{r} / \mathrm{min}$ to collect the supernatant. Repeated this procedure twice, mixed the supernatants, and diluted to $500 \mathrm{~mL}$ with ultra-pure water to ensure that the methanol content was $2 \%$. The diluted extract was further purified by solid-phase extraction. The specific steps were as follows: firstly, added $0.5 \mathrm{~g}$ of $\mathrm{Na}_{2}$ EDTA into each bottle to precipitate metal ions in the water and avoid clogging after suction filtration of the extract; activated the extraction cartridge with $5 \mathrm{~mL}$ methanol and $5 \mathrm{~mL}$ ultra-pure water in turn; then loaded the sample at a speed of $5 \mathrm{~mL} / \mathrm{min}$; after loading, rinsed the cartridge with $5 \mathrm{~mL}$ ultra-pure water 3 times and then subject the extraction liquid to air-drying for $15 \mathrm{~min}$. The residue extract enriched was then eluted with $6 \mathrm{~mL}$ methanol/dichloromethane/acetone (2:2:1) solution. Blew the eluent on a nitrogen dryer at $40{ }^{\circ} \mathrm{C}$ to nearly dryness, then diluted the volume to $1 \mathrm{~mL}$ with methanol solution; added $0.1 \mu \mathrm{g}$ of internal standard sulfamethoxazole-D4 before passing the solution through a $0.22 \mu \mathrm{m}$ polyethersulfone needle type filter. Finally, the samples were injected and analyzed by a UHPLC-MS/MS. The ultra-high pressure liquid chromatography-mass spectrometer used in the experiment is Waters AcquityTM Ultra Performance LC in series Quattro Premier Micromass (Waters, USA); the chromatography column is Waters AcquityTM UPLC BEH C18 (50mmx2.1 mm, $1.7 \mathrm{pm})$; the ionization source is Electrospray ionization source (ESI), and the detector is Quattro Premier Micromass, MRM detection mode, Masslynx 4.0 workstation (Waters, USA).

\section{Results and discussion}

\subsection{Solubilization characteristics of SS after pre-treatments}

We tested the effect of thermal pre-treatment on COD solubilization characteristics of SS from $60^{\circ} \mathrm{C}$ to $100^{\circ} \mathrm{C}$, with or without the combination of sonication (Fig. 1a). Results showed that the COD-based solubilization of the sludge mixture increased with temperature, which was consistent with previous studies (Liu et al., 2020; Razavi et al., 2019). Fig. 1a indicated that pre-treatments increased SCOD of the control from $108 \pm 5 \mathrm{mg} / \mathrm{L}$ to $876-3516 \mathrm{mg} / \mathrm{L}$, while SCOD increased from $1364 \pm 68 \mathrm{mg} / \mathrm{L}$ at $60{ }^{\circ} \mathrm{C}$ to $2635 \pm 132 \mathrm{mg} / \mathrm{L}$ at $100{ }^{\circ} \mathrm{C}$ by the thermal pre-treatment alone. Thermal pre-treatment at $100{ }^{\circ} \mathrm{C}$ combined with $40 \mathrm{kHz}$ ultrasonic pre-treatment reached the maximum SCOD $(3516 \pm 176 \mathrm{mg} / \mathrm{L})$, representing about 32 times of the control. This was higher than the study by Dhar et al., which showed a five-fold increase in SCOD compared to the control by ultrasound-thermal pretreatment $\left(90^{\circ} \mathrm{C}\right)$ (Dhar et al., 2012). The ratio of soluble versus total COD (SCOD/TCOD) reached $6.15 \%$ at $100{ }^{\circ} \mathrm{C}$ (Fig. $\left.1 \mathrm{~b}\right)$, much lower than the study of Dhar et al. (2012), where the same specific energy input $(10,000 \mathrm{~kJ} / \mathrm{kg}$ TSS) increased the SCOD/TCOD ratio from $6 \%$ to $33 \%$. The results implied that the SS used in this study was much more difficult to disintegrate than the study of Dhar et al. (2012).

We can see from Fig. 2(a) and (b) that thermal pre-treatment and ultrasonic pre-treatment could increase dissolution of polysaccharides and proteins particularly, which is comparable to the previous results (Dhar et al., 2012; Neumann et al., 2017; Zhang et al., 2019). Moreover, compared with the control, the thermal combined ultrasonic pretreatment achieved the maximum dissolution of soluble protein ( $473.0 \mathrm{VS} 4.8 \mathrm{mg} / \mathrm{L}$ ) and the maximum dissolution of soluble polysaccharide (478.0 VS $24.0 \mathrm{mg} / \mathrm{L}$ ). This was higher than Neumann et al.'s study that the soluble concentration of protein was increased by $252-674 \%$ after the ultrasound and low temperature $\left(55^{\circ} \mathrm{C}\right)$ pretreatments (Neumann et al., 2017). It was noteworthy that the content of soluble proteins increased rapidly from $90{ }^{\circ} \mathrm{C}$ to $100{ }^{\circ} \mathrm{C}$. The higher solubilization of polysaccharides versus proteins below $90{ }^{\circ} \mathrm{C}$ might be caused by higher energy required to break proteins into oligomers and monomers (Fig. 2b). The phenomenon was well explained by the higher solubility and smaller size of polysaccharide oligomers and monomers (Chen et al., 2017). Fig. 2c showed the change of $\mathrm{NH}_{4}^{+}-\mathrm{N}$ concentration under different pre-treatments, which was mainly reflected in the decrease of its concentration with increasing temperature. This phenomenon may be caused by the coagulation process that could entrap $\mathrm{NH}_{4}^{+}$ groups and/or react with the solid matrix to form new, relatively stable bonds to alleviate ammonium inhibition of the subsequent $\mathrm{AD}$ process 
Soluble chemical oxygen demand $(\mathrm{mg} / \mathrm{L})$

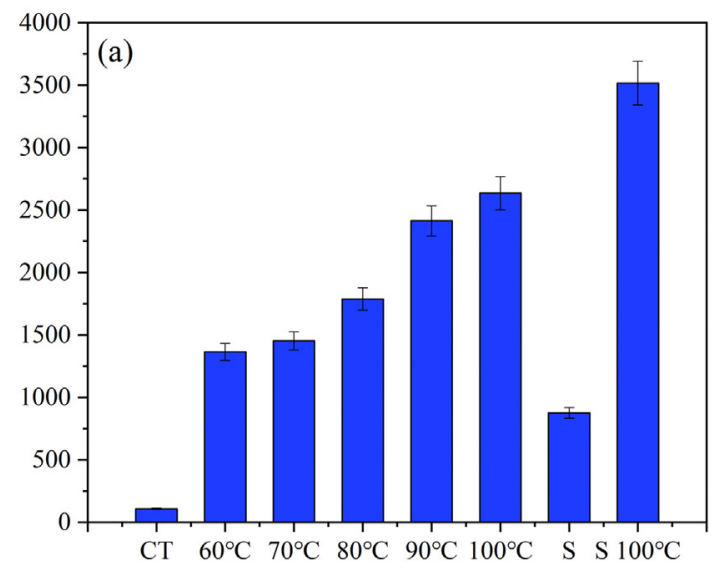

Thermal and/or ultrasonic pretreatments
$\mathrm{SCOD} / \mathrm{TCOD}(\mathrm{w} \%)$

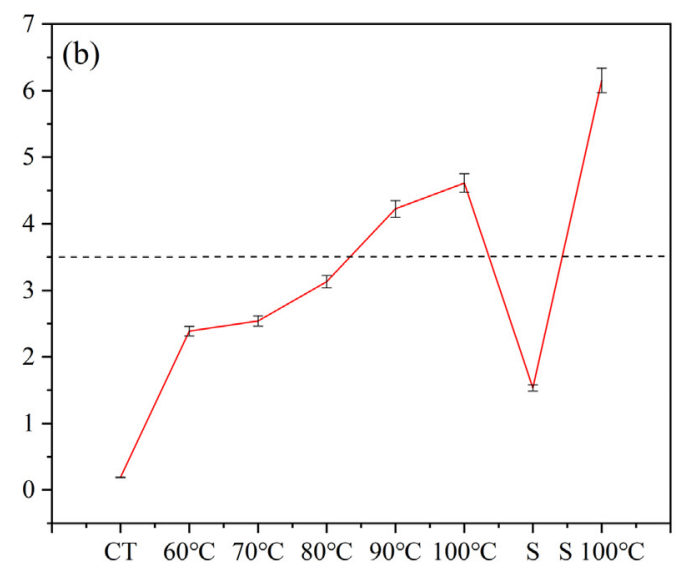

Thermal and/or ultrasonic pretreatments

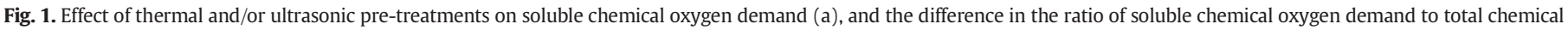
oxygen demand (b). Error bars in all figures below represent the standard deviation of triplicate samples.

(Rajagopal et al., 2013). It was found that ultrasonic pre-treatment increased the concentration of $\mathrm{NH}_{4}^{+}-\mathrm{N}$ in SS due to the dissolution of a large amount of organic matter. However, the $\mathrm{NH}_{4}^{+}-\mathrm{N}$ concentration (994 $\mathrm{mg} / \mathrm{L})$ in this study did not reach the highest value $(3500 \mathrm{mg} / \mathrm{L})$ mentioned by Liu et al. that can significantly inhibit the AD process (Liu et al., 2021b).

The mechanism of how thermal pre-treatment and ultrasonic pretreatment improve AD performances is proposed in Fig. 2d. Firstly the thermal pre-treatment is to put the sludge flocculent and the bacterial micelles bulk under the heating condition of a water bath; the extracellular polymers and macromolecular organic matter in the sludge are then hydrolyzed and the cell wall of the microorganisms is destroyed; while the process strengthens the biodegradability of the material and improves the fluidity of the material (Kor-Bicakci and Eskicioglu, 2019). The contributing factors of ultrasonic sludge disintegration include sonochemical effects, high mechanical forces, and thermal effects (Pilli et al., 2011). Sonication leads to the formation of cavitation bubbles in the liquid phase; these bubbles grow and explode violently, causing high shearing forces in the surrounding liquid phase of the waste and radicals' formation (Lizama et al., 2017; Luo et al., 2014; Pilli et al., 2011). Therefore, it could be inferred that the thermal combined ultrasonic pre-treatment was simultaneously affected and strengthened by the above two mechanisms, which had also been verified in our work. Overall, our results on pre-treatments showed a notable increase of soluble chemical oxygen demand, soluble polysaccharide and soluble proteins with temperature and sonication. While the combination of thermal and ultrasonic pre-treatment could greatly enhance the above effects. As far as the concentration of $\mathrm{NH}_{4}^{+}-\mathrm{N}$ was concerned, most pre-treatments would reduce $\mathrm{NH}_{4}^{+}-\mathrm{N}$ in the supernatant except the ultrasonic pre-treatment; nevertheless, the increase of $\mathrm{NH}_{4}^{+}-\mathrm{N}$ in supernatant after ultrasonic pre-treatment was not high enough to cause obvious inhibition on performances of the the subsequent $\mathrm{AD}$ process.

\subsection{Change of DOMs composition and reduction of typical antibiotics}

Fig. 3 demonstrated effects of thermal and sonication pretreatments on DOMs composition of SS supernatants. The identifiable central fluorescence positions of commonly DOMs were shown in Supplementary materials (Table S1). The results indicated that the main organic component was soluble microbial products in the control group, appearing as an inclined green line in zone IV (Fig. 3a). The $100{ }^{\circ} \mathrm{C}$ thermal pre-treatment induced an increase of green spots in zones I, II, and IV (Fig. 3b), which were ascribed to tyrosine-like, tryptophan-like, and soluble microbial products, respectively. These results were consistent with the changes in the fluorescence peaks of the I and IV regions of food waste after short-term thermal treatment reported by (Li et al., 2014), indicating that the metabolites were mainly composed of biodegradable DOMs and slightly hard-biodegradable DOMs. The sonication pre-treatment showed a similar change, albeit less intense (Fig. 3c). This was in line with the previous study by Chen et al. that ultrasonic pretreatment could destroy extracellular polymers and help dissolve insoluble organic matter (Chen et al., 2017). Thermal combined ultrasonic pre-treatment showed in addition green, yellow and red spots in zone III, fulvic acid-like; zone V, humic acid-like (Fig. 3d). It proved that the combined method had an important effect on the slow-biodegradable DOMs such as fulvic acids and humic acids. Combined treatments in this study showed better performance than separate pre-treatments ( $\mathrm{Li}$ et al., 2014; Wang et al., 2018). Overall, in terms of promoting the dissolution of DOMs in SS, performances of the pre-treatment strategies lined in the following descending order: $100{ }^{\circ} \mathrm{C}$ thermal combined with ultrasonic pre-treatment $>100{ }^{\circ} \mathrm{C}$ thermal pre-treatment $>$ ultrasound pre-treatment $>$ the control group.

The effect of pre-treatments on effluent antibiotic levels were shown in Fig.4, sulfamethoxazole was observed only in the control and the thermal pre-treatment after 3 days of incubation, indicating that thermal and/or ultrasonic pre-treatment could rapidly degrade sulfamethoxazole in the early stage of AD. Tetracycline presented the highest levels in the whole process, and the results did not indicate a noticeable reduction level in the soluble fraction of the treated sludge. On the contrary, in the study of Zhang \& Li, tetracyclines had a relatively high removal efficiency (62.9-58.5\%), but the relative dissolution rate was also high or even higher than the degradation rate, resulting in unsatisfactory effluents (Zhang and Li, 2018). This study indicated that biodegradable substances generated during the pre-treatment process was vital to reduction of antibiotics. The results could be explained with the active microbial metabolism. When the co-metabolism effect is not significant, the easily biodegradable substances would compete with the biodegradation of the target antibiotic. Compared to digestion results on day 3 and day 18, the removal of sulfamethazine after pretreatment was more prominent, especially in the ultrasound group alone, which was better than the combined pre-treatment. However, the single ultrasonic pre-treatment would increase the content of roxithromycin. The de-conjugation might cause the negative removal efficiency of roxithromycin from the sludge during the treatment process, indicating the roxithromycin was prevalent in SS (Ni et al., 2020). There are many applications using three-dimensional fluorescence spectroscopy 
Soluble polysaccharides (mg/L)

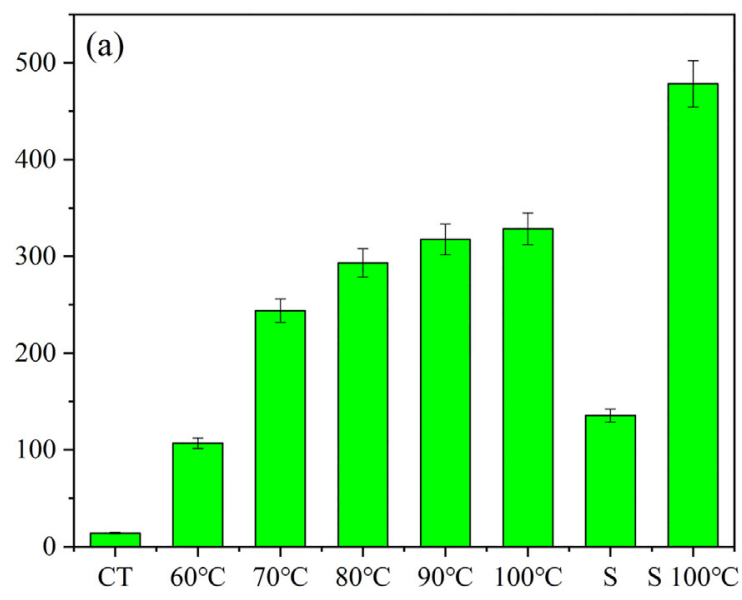

Thermal and/or ultrasonic pretreatments

$$
\mathrm{NH}_{4}^{+}-\mathrm{N}(\mathrm{mg} / \mathrm{L})
$$

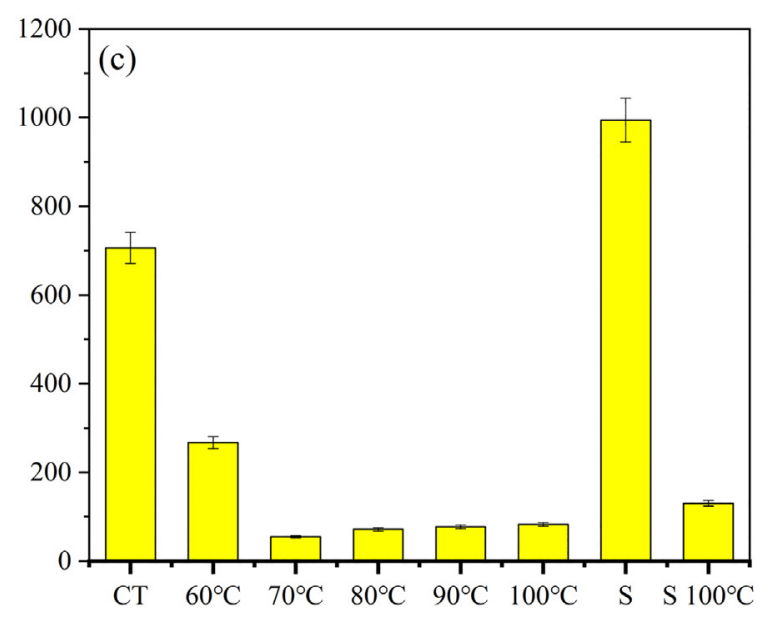

Thermal and/or ultrasonic pretreatments
Soluble proteins $(\mathrm{mg} / \mathrm{L})$

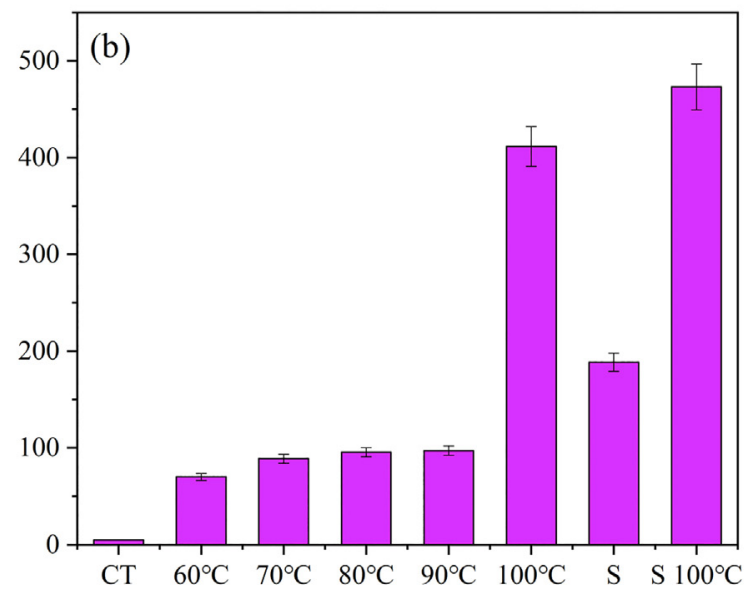

Thermal and/or ultrasonic pretreatments

(d)
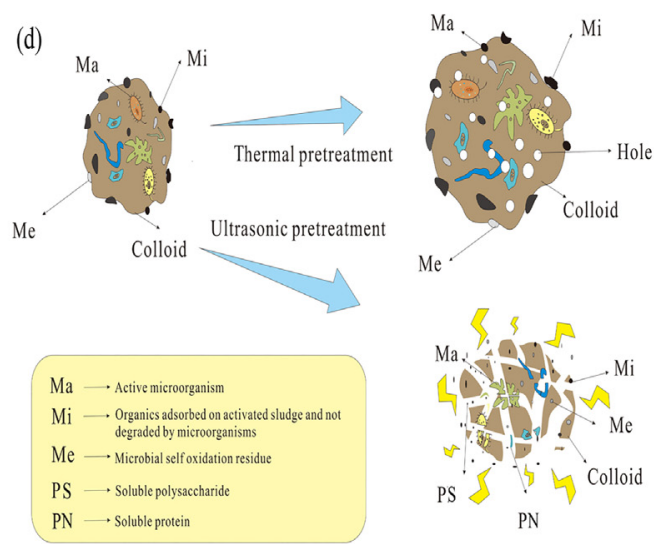

Fig. 2. Effect of thermal and/or ultrasonic pre-treatments on soluble polysaccharides (a), soluble proteins (b), ammonia nitrogen (c), and mechanisms of contributing effects (d).

to study the content of organic matter, but few studies link the content of organic matter detected by this method to the degradation of antibiotics. Combined Figs. 3 and 4, it indicated that the increase of tyrosine-like and tryptophan-like substances in the thermal pre-treatment and the thermal combined ultrasonic pre-treatment was more obvious than that of the control and the ultrasonic pre-treatment group. The corresponding thermal pre-treatment group and thermal combined ultrasonic pretreatment group degraded sulfamethoxazole rapidly. Correspondingly, in the study of Wang et al., it was found that during $\mathrm{AD}$, high concentrations of sulfa antibiotics caused a decrease in the content of tyrosine-like substances (Wang et al., 2020). It could be inferred that the content of tyrosine-like and tryptophan-like substances are positively correlated with the degradation of sulfamethoxazole. Meanwhile, the fulvic acidlike and humic acid-like substances in the thermal pre-treatment combined with ultrasonic pre-treatment group increased significantly than the other groups. After 18 days of digestion, the content of roxithromycin and tetracycline decreased to the least among the four groups. Interaction between tetracycline and extracellular polymeric substances was a dynamic process, and the interaction could be static quenching (Hou et al., 2016). It could be inferred that the content of fulvic acid-like and humic acid-like substances are positively correlated with the degradation of roxithromycin and tetracycline. These inferences provided a new strategy for the degradation of antibiotics in sludge, such as using this dynamic interaction to selectively supplement or reduce the concentration of different organic substances in the sludge to increase the degradation of antibiotics.

\subsection{Enhanced biogas production under different pre-treatments}

As shown in Fig. 5a, the biogas production could be calculated according to the daily biogas production curve; four different biogas production groups were obtained through statistical calculations: $555.2 \mathrm{~mL}$ in the untreated group, $540.1 \mathrm{~mL}$ in the $100{ }^{\circ} \mathrm{C}$ pretreatment group, $587.5 \mathrm{~mL}$ in the ultrasonic pre-treatment group, and $660.5 \mathrm{~mL}$ in the $100{ }^{\circ} \mathrm{C}$ then ultrasonic pre-treatment group. By comparison, it was found that the ultrasonic pre-treatment alone barely had any effect on biogas production. The biogas production rate increased $19.0 \%$ after the combination of sonication and $100{ }^{\circ} \mathrm{C}$ thermal pre-treatment, slightly higher than the study of Şahinkaya and Sevimli, where the total methane production in the sonothermalized reactor increased by $13.6 \%$ (Şahinkaya and Sevimli, 2013). But curiously, the biogas production decreased after $100{ }^{\circ} \mathrm{C}$ 


\section{Effect of sludge pre-treatment on organic matter composition}
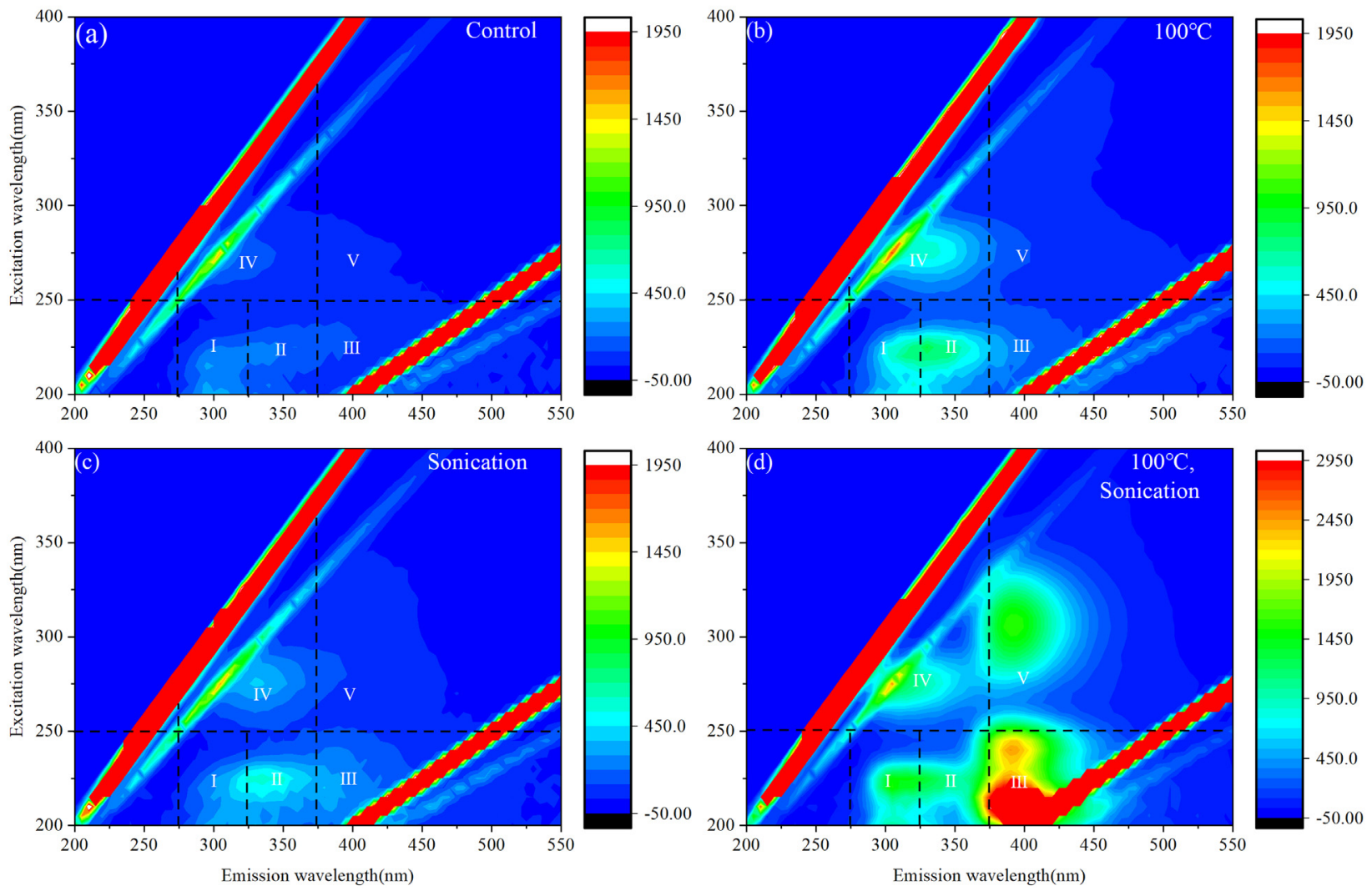

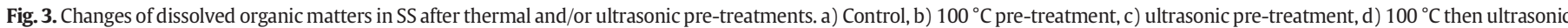
pre-treatments. Areas I-V refer to the main categories of organic matter: I) tyrosine-like, II) tryptophan-like, III) fulvic-acid like, IV) soluble microbial products, V) humic acid-like.

thermal pre-treatment in this study. This might be due to the theory that the thermal pre-treatment promoted the Maillard reaction and melanin production proposed by (Liu et al., 2021). In another

\section{Antibiotics (ng/L)}

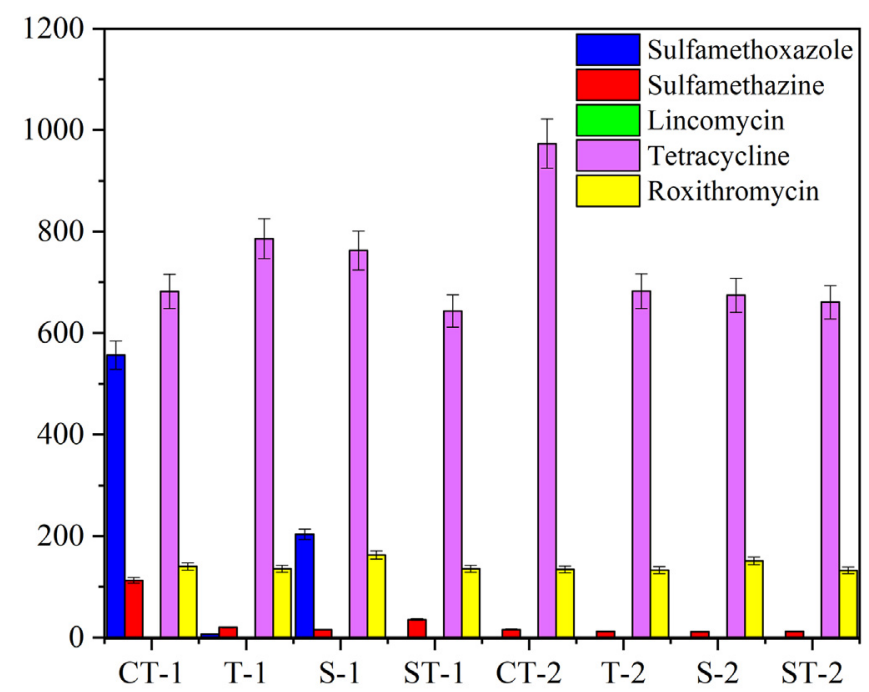

Digestion groups

Fig. 4. Antibiotic content in different digestion groups. CT, T, S, and ST stand for control, thermal pre-treatment, ultrasonic pre-treatment and thermal combined ultrasonic pretreatment, respectively. The suffix -1 represents results on the 3rd day, and the suffix -2 represents results on the 18 th day. investigation ultrasonic pre-treatment at a moderate specific energy ratio increased biogas production by $15 \%$ (Appels et al., 2008), but ultrasound pre-treatment alone did not improve biogas production in this study, implying that although the long-term ultrasound pretreatment released total organic carbon (TOC) from sludge continuously, 60 min of ultrasound would also cause an excessive increase in nitrogen in the water phase, which harmed the inoculum. Using the changing profiles of TOC, TN, and VS concentration with pretreatment time to evaluate the effect of ultrasonic pre-treatment could be an option to evaluate comprehensive effects of ultrasonic pre-treatment on SS disposal (Martín et al., 2015).

Thus, the digested sludge samples on the 3rd and the 18th day were analyzed for TS, VS, SCOD, STN, STP and CST in this study. Fig. 5b indicated that the highest levels of SCOD were observed on the 3rd day of digestion with values from $4024 \mathrm{mg} / \mathrm{L}$ to $4616 \mathrm{mg} / \mathrm{L}$, whereas only $1844-3024 \mathrm{mg} / \mathrm{L}$ SCOD were obtained after 18 days of digestion. All pre-treatments presented higher SCOD than control on day 3 , whereas the reverse was observed on day 18 , indicating that the thermal pre-treatment and ultrasonic pre-treatment accelerated the $A D$ and shortened the reaction time (Khanh Nguyen et al., 2021). As shown in Fig. 5c, thermal combined with ultrasonic pre-treatment could increase the degradation rate of VS significantly compared with the control (54.4 VS 23.4\%). The combined pretreatment method presented the greatest CST reduction (85\%) comparing to the control, higher than that of ultrasonic pre-treatment (75\%) alone (Shao et al., 2010). Overall, both thermal and ultrasonic pre-treatment could enhance biogas production of SS, increase sludge biodegradability and improve sludge dewatering performance; the combination of the two pre-treatment methods could promote the performances of SS disposal comparing with the individual pre-treatments. 
Biogas production $(\mathrm{mL})$

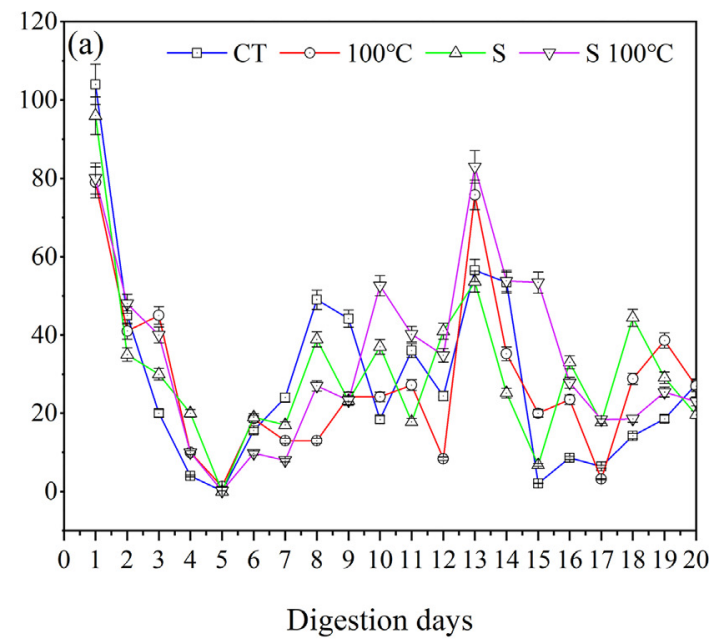

Soluble chemical oxygen demand $(\mathrm{mg} / \mathrm{L})$

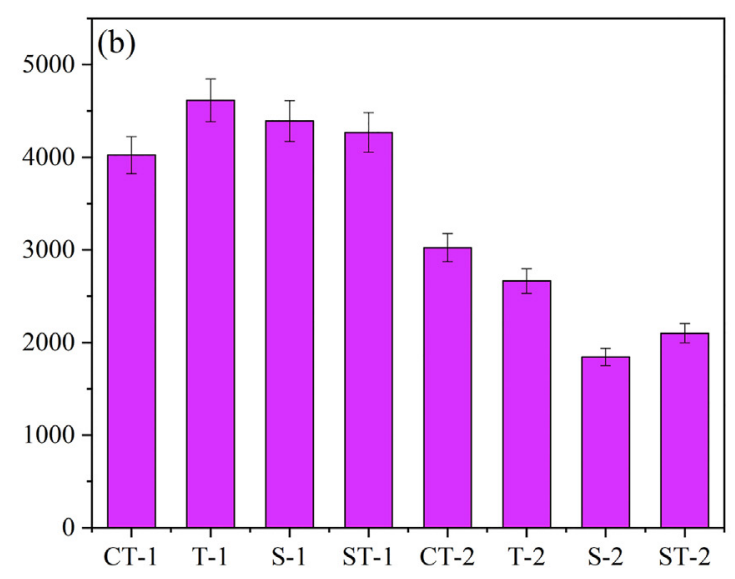

Thermal and/or ultrasonic pretreatments

Removal rates (w\%)

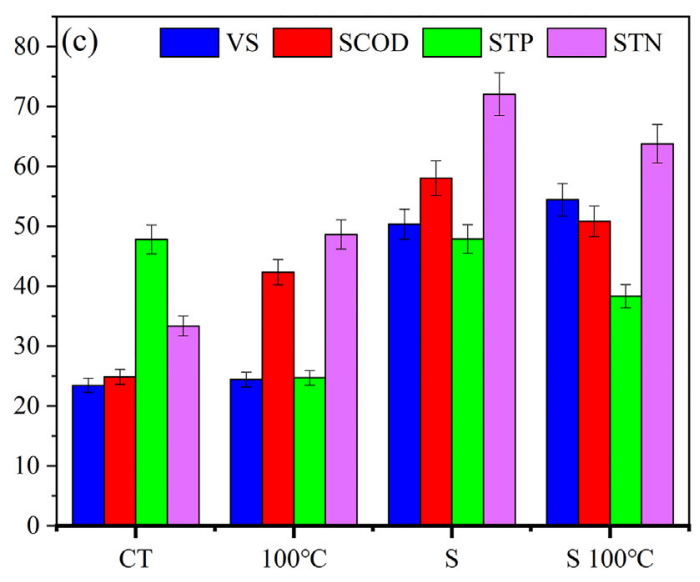

Digestion groups

Fig. 5. The amount of biogas produced during digestion (a); SCOD in the digestion groups (b); the removal rates of VS, SCOD, STP, and STN in digestion groups (c). CT, T, S, and ST stand for control, thermal pre-treatment, ultrasonic pre-treatment and thermal combined ultrasonic pre-treatment, respectively. The suffix -1 represents results on the 3rd day, and the suffix -2 represents results on the 18 th day.

\subsection{Environmental implications}

Different from other investigations, this study combines two methods of thermal pre-treatment and ultrasonic pre-treatment for AD of SS, which maximizes the dissolution of organic matter in SS and breaks the barriers in the hydrolysis stage. Compared with separate pre-treatments, this method shortens the reaction time, increases the biogas production on the one hand, and improves the dewaterability of the sludge on the other hand. Most importantly, the relationship between the migration of organic matter in the SS after pretreatment and the degradation of antibiotics was analyzed by means of three-dimensional fluorescence, which proved that the combined pre-treatment method could effectively increase the degradation rate of antibiotics in the sludge. The research results in this article could be applied to actual medium and large AD systems. It could greatly improve reaction efficiency, increase production rate, and reduce sludge output. In addition, sludge with lower antibiotic content could be obtained, and treatment costs could be reduced. The microbial community in the process and the mechanism of increasing the degradation rate of antibiotics and resistant genes are remaining challenges for future investigations after this study.

\section{Conclusions}

In this study, the effects of thermal pre-treatment, ultrasonic pretreatment, and thermal combined ultrasonic pre-treatment before and after AD of SS were comprehensively investigated. In conclusion, thermal combined ultrasonic pre-treatment is not only the best choice for solubilizing organics before $\mathrm{AD}$, but also a promotion to the performance of AD. Compared with the control, thermal combined ultrasonic pre-treatment of sludge obtained the maximum SCOD concentration (3516 VS $108 \mathrm{mg} / \mathrm{L}$ ), soluble protein concentration (473 VS $4.8 \mathrm{mg} / \mathrm{L}$ ), and polysaccharide concentration ( $478 \mathrm{VS} 24 \mathrm{mg} / \mathrm{L}$ ). Thermal combined ultrasonic pre-treatment promoted the decomposition of SS better than individual pre-treatments, which could improve the efficiency of subsequent $\mathrm{AD}$ and shorten the reaction time. After $\mathrm{AD}$, the combined pretreatment obtained the maximum biogas increase, reduced the amount of sludge and improved the dewatering performance of the sludge, comparing to the existing separate thermal pre-treatments and ultrasonic pre-treatments. In addition, the combined method could also effectively reduce the content of antibiotics, especially the sulfa antibiotics in SS.

Supplementary data to this article can be found online at https://doi. org/10.1016/j.scitotenv.2021.147862.

\section{CRediT authorship contribution statement}

- Hongbo Liu: Conceptualization, funding acquisition, project administration, supervision, original draft.

- Xingkang Wang: Methodology, lab investigation, mechanism modelling, original draft.

- Song Qin: Lab investigation.

- Wenjia Lai: Resource, funding acquisition, review \& editing.

- Xin Yang: Lab investigation.

- Suyun Xu: Supervision, original draft, review \& editing.

- Eric Lichtfouse: Review \& editing.

\section{Declaration of competing interest}

The authors have declared no conflict of interest.

\section{Acknowledgments}

This work was co-supported by the National Natural Science Foundation of China (No. 52070130) and the Shuguang Project of Shanghai (Education and Scientific Research Project of Shanghai, 18SG45). 


\section{References}

Anjum, M., Al-Makishah, N.H., Barakat, M.A., 2016. Wastewater sludge stabilization using pre-treatment methods. Process. Saf. Environ. Prot. 102, 615-632. https://doi.org/ 10.1016/j.psep.2016.05.022.

Appels, L., Dewil, R., Baeyens, J., Degrève, J., 2008. Ultrasonically enhanced anaerobic digestion of waste activated sludge. Int. J. Sustain. Eng. 1 (2), 94-104. https://doi.org/ 10.1080/19397030802243319.

Barber, W.P.F., 2016. Thermal hydrolysis for sewage treatment: a critical review. Water Res. 104, 53-71. https://doi.org/10.1016/j.watres.2016.07.069.

Buaisha, Magdi, Balku, Saziye, Özalp-Yaman, Şeniz, 2020. Heavy metal removal investigation in conventional activated sludge systems. Civil Eng. J. 6, 470-477. https://doi.org/ 10.28991/cej-2020-03091484

Carlsson, M., Lagerkvist, A., Morgan-Sagastume, F., 2012. The effects of substrate pretreatment on anaerobic digestion systems: a review. Waste Manag. 32 (9), 1634-1650. https://doi.org/10.1016/j.wasman.2012.04.016.

Chen, W., Gao, X., Xu, H., Cai, Y., Cui, J., 2017. Influence of extracellular polymeric substances (EPS) treated by combined ultrasound pretreatment and chemical reflocculation on water treatment sludge settling performance. Chemosphere 170, 196-206. https://doi.org/10.1016/j.chemosphere.2016.12.004.

Dhar, B.R., Nakhla, G., Ray, M.B., 2012. Techno-economic evaluation of ultrasound and thermal pretreatments for enhanced anaerobic digestion of municipal waste activated sludge. Waste Manag. 32 (3), 542-549. https://doi.org/10.1016/j.wasman.2011.10.007.

Ding, A., Zhang, R., Ngo, H.H., He, X., Ma, J., Nan, J., Li, G., 2021. Life cycle assessment of sewage sludge treatment and disposal based on nutrient and energy recovery: a review. Sci. Total Environ. 769, 144451. https://doi.org/10.1016/j.scitotenv.2020.144451.

Han, D., Lee, C.Y., Chang, S.W., Kim, D.J., 2017. Enhanced methane production and wastewater sludge stabilization of a continuous full scale thermal pretreatment and thermophilic anaerobic digestion. Bioresour. Technol. 245 (Pt A), 1162-1167. https:// doi.org/10.1016/j.biortech.2017.08.108.

Harrison, E.Z., Oakes, S.R., Hysell, M., Hay, A., 2006. Organic chemicals in sewage sludges. Sci. Total Environ. 367 (2), 481-497. https://doi.org/10.1016/j.scitotenv.2006.04.002.

Hassan, M., Zhao, C., Ding, W., 2020. Enhanced methane generation and biodegradation efficiencies of goose manure by thermal-sonication pretreatment and organic loading management in CSTR. Energy 198, 117370. https://doi.org/10.1016/j.energy.2020.117370.

Hou, G., Hao, X., Zhang, R., Wang, J., Liu, R., Liu, C., 2016. Tetracycline removal and effect on the formation and degradation of extracellular polymeric substances and volatile fatty acids in the process of hydrogen fermentation. Bioresour. Technol. 212, 20-25. https://doi.org/10.1016/j.biortech.2016.03.156.

Huang, J., Liang, J., Yang, X., Zhou, J., Liao, X., Li, S., Zheng, L., Sun, S., 2020. Ultrasonic coupled bioleaching pretreatment for enhancing sewage sludge dewatering: simultaneously mitigating antibiotic resistant genes and changing microbial communities. Ecotoxicol. Environ. Saf. 193, 110349. https://doi.org/10.1016/j.ecoenv.2020.110349.

Khanh Nguyen, V., Kumar Chaudhary, D., Hari Dahal, R., Hoang Trinh, N., Kim, J., Chang, S.W., Hong, Y., Duc La, D., Nguyen, X.C., Hao Ngo, H., Chung, W.J., Nguyen, D.D., 2021. Review on pretreatment techniques to improve anaerobic digestion of sewage sludge. Fuel 285, 119105. https://doi.org/10.1016/j.fuel.2020.119105.

Kor-Bicakci, G., Eskicioglu, C., 2019. Recent developments on thermal municipal sludge pretreatment technologies for enhanced anaerobic digestion. Renew. Sust. Energ. Rev. 110, 423-443. https://doi.org/10.1016/j.rser.2019.05.002.

Kumar Biswal, B., Huang, H., Dai, J., Chen, G.-H., Wu, D., 2020. Impact of low-thermal pretreatment on physicochemical properties of saline waste activated sludge, hydrolysis of organics and methane yield in anaerobic digestion. Bioresour. Technol. 297, 122423. https://doi.org/10.1016/j.biortech.2019.122423.

Li, M., Xia, T., Zhu, C., Xi, B., Jia, X., Wei, Z., Zhu, J., 2014. Effect of short-time hydrothermal pretreatment of kitchen waste on biohydrogen production: fluorescence spectroscopy coupled with parallel factor analysis. Bioresour. Technol. 172, 382-390. https://doi.org/10.1016/j.biortech.2014.09.040.

Li, C., Zhang, G., Zhang, Z., Ma, D., Wang, L., Xu, G., 2015. Hydrothermal pretreatment for biogas production from anaerobic digestion of antibiotic mycelial residue. Chem. Eng. J. 279, 530-537. https://doi.org/10.1016/j.cej.2015.05.073.

Liao, X., Li, H., Cheng, Y., Chen, N., Li, C., Yang, Y., 2014. Process performance of high-solids batch anaerobic digestion of sewage sludge. Environ. Technol. 35 (21), 2652-2659. https://doi.org/10.1080/09593330.2014.916756.

Liu, X., Wang, Q., Tang, Y., Pavlostathis, S.G., 2020. Hydrothermal pretreatment of sewage sludge for enhanced anaerobic digestion: resource transformation and energy balance. Chem. Eng. J., 127430 https://doi.org/10.1016/j.cej.2020.127430.

Liu, J., Yin, J., He, X., Chen, T., Shen, D., 2021. Optimizing food waste hydrothermal parameters to reduce Maillard reaction and increase volatile fatty acid production. J. Environ. Sci. 103, 43-49. https://doi.org/10.1016/j.jes.2020.09.032.

Liu, Y., Xiao, Q., Jia, Z., Wang, C., Ye, X., Du, J., Kong, X., Xi, Y., 2021b. Relieving ammonia nitrogen inhibition in high concentration anaerobic digestion of rural organic household waste by Prussian blue analogue nanoparticles addition. Bioresour. Technol. 330, 124979. https://doi.org/10.1016/j.biortech.2021.124979.

Lizama, A.C., Figueiras, C.C., Herrera, R.R., Pedreguera, A.Z., Ruiz Espinoza, J.E., 2017. Effects of ultrasonic pretreatment on the solubilization and kinetic study of biogas production from anaerobic digestion of waste activated sludge. Int. Biodeterior. Biodegradation 123, 1-9. https://doi.org/10.1016/j.ibiod.2017.05.020.

Luo, J., Fang, Z., Smith, R.L., 2014. Ultrasound-enhanced conversion of biomass to biofuels. Prog. Energy Combust. Sci. 41, 56-93. https://doi.org/10.1016/j.pecs.2013.11.001.
Martín, M.Á., González, I., Serrano, A., Siles, J.Á., 2015. Evaluation of the improvement of sonication pre-treatment in the anaerobic digestion of sewage sludge. J. Environ. Manag. 147, 330-337. https://doi.org/10.1016/j.jenvman.2014.09.022.

Memon, Muhammad, Memon, Abdul, 2020. Wheat straw optimization via its efficient pretreatment for improved biogas production. Civil Eng. J. 6, 1056-1063. https:// doi.org/10.28991/cej-2020-03091528.

Neumann, P., González, Z., Vidal, G., 2017. Sequential ultrasound and low-temperature thermal pretreatment: process optimization and influence on sewage sludge solubilization, enzyme activity and anaerobic digestion. Bioresour. Technol. 234, 178-187. https://doi.org/10.1016/j.biortech.2017.03.029.

Nguyen, D.D., Yoon, Y.S., Nguyen, N.D., Bach, Q.V., Bui, X.T., Chang, S.W., Le, H.S., Guo, W. Ngo, H.H., 2017. Enhanced efficiency for better wastewater sludge hydrolysis conversion through ultrasonic hydrolytic pretreatment. J. Taiwan Inst. Chem. Eng. 71, 244-252. https://doi.org/10.1016/j.jtice.2016.12.019.

Ni, B.-J.,Zeng S, Wei, W., Dai, X, Sun, J., 2020. Impact of roxithromycin on waste activated sludge anaerobic digestion: methane production, carbon transformation and antibiotic resistance genes. Sci. Total Environ. 703, 134899. https://doi.org/10.1016/j. scitotenv.2019.134899.

Pilli, S., Bhunia, P., Yan, S., LeBlanc, R.J., Tyagi, R.D., Surampalli, R.Y., 2011. Ultrasonic pretreatment of sludge: a review. Ultrason. Sonochem. 18 (1), 1-18. https://doi.org/ 10.1016/j.ultsonch.2010.02.014.

Public, A., Association, H., 1998. APHA standard methods for the examination of water and wastewater. Am. J. Public Health Nations Health 56 (3), 387. https://doi.org/10.2105/ AJPH.51.6.940-a.

Raheem, A., Sikarwar, V.S., He, J., Dastyar, W., Dionysiou, D.D., Wang, W., Zhao, M., 2018 Opportunities and challenges in sustainable treatment and resource reuse of sewage sludge: a review. Chem. Eng. J. 337, 616-641. https://doi.org/10.1016/j.cej.2017.12.149.

Rajagopal, R., Massé, D.I., Singh, G., 2013. A critical review on inhibition of anaerobic digestion process by excess ammonia. Bioresour. Technol. 143, 632-641. https://doi. $\operatorname{org} / 10.1016 /$ j.biortech.2013.06.030.

Razavi, A.S., Hosseini Koupaie, E., Azizi, A., Hafez, H., Elbeshbishy, E., 2019. Hydrothermal pretreatment of source separated organics for enhanced solubilization and biomethane recovery. Bioresour. Technol. 274, 502-511. https://doi.org/10.1016/j. biortech.2018.12.024.

Şahinkaya, S., Sevimli, M.F., 2013. Sono-thermal pre-treatment of waste activated sludge before anaerobic digestion. Ultrason. Sonochem. 20 (1), 587-594. https://doi.org/ 10.1016/j.ultsonch.2012.07.006.

Scharnberg, Allan, Loreto, Adrison, Alves, Annelise, 2020. Optical and structural characterization of Bi2FexNbO7 nanoparticles for environmental applications. Emerg. Sci. J. 4 11-17. https://doi.org/10.28991/esj-2020-01205.

Shao, L., Wang, G., Xu, H., Yu, G., He, P., 2010. Effects of ultrasonic pretreatment on sludge dewaterability and extracellular polymeric substances distribution in mesophilic anaerobic digestion. J. Environ. Sci. 22 (3), 474-480. https://doi.org/10.1016/S10010742(09)60132-7.

Sun, C., Li, W., Chen, Z., Qin, W., Wen, X., 2019. Responses of antibiotics, antibiotic resistance genes, and mobile genetic elements in sewage sludge to thermal hydrolysis pre-treatment and various anaerobic digestion conditions. Environ. Int. 133, 105156. https://doi.org/10.1016/j.envint.2019.105156.

Tang, M., Li, F., Yang, M., Zhang, Y., 2020. Degradation of kanamycin from production wastewater with high-concentration organic matrices by hydrothermal treatment J. Environ. Sci. 97, 11-18. https://doi.org/10.1016/j.jes.2020.04.032.

Tiehm, A., Nickel, K., Zellhorn, M., Neis, U., 2001. Ultrasonic waste activated sludge disintegration for improving anaerobic stabilization. Water Res. 35 (8), 2003-2009. https://doi.org/10.1016/S0043-1354(00)00468-1.

Tyagi, V.K., Lo, S.L., Appels, L., Dewil, R., 2014. Ultrasonic treatment of waste sludge: a review on mechanisms and applications. Crit. Rev. Environ. Sci. Technol. 44 (11) 1220-1288. https://doi.org/10.1080/10643389.2013.763587.

Wang, H., Cai, W.-W., Liu, W.-Z., Li, J.-Q., Wang, B., Yang, S.-C., Wang, A.-J., 2018 Application of sulfate radicals from ultrasonic activation: disintegration of extracellular polymeric substances for enhanced anaerobic fermentation of sulfate-containing waste-activated sludge. Chem. Eng. J. 352, 380-388. https://doi.org/10.1016/j. cej.2018.07.029.

Wang, S., Yuan, R., Chen, H., Wang, F., Zhou, B., 2020. Effect of sulfonamides on the dissolved organic matter fluorescence in biogas slurry during anaerobic fermentation according to the PARAFAC analysis. Process. Saf. Environ. Prot. 144, 253-262. https://doi.org/10.1016/j.psep.2020.07.033.

Wen, C., 2003. Fluorescence excitation-emission matrix regional integration to quantify spectra for dissolved organic matter. Environ. Sci. Technol. 24 (37). https://doi.org/ 10.1021/es034354c.

Yang, G., Zhang, G., Wang, H., 2015. Current state of sludge production, management, treatment and disposal in China. Water Res. 78, 60-73. https://doi.org/10.1016/j. watres.2015.04.002.

Zhang, X., Li, R., 2018. Variation of antibiotics in sludge pretreatment and anaerobic digestion processes: degradation and solid-liquid distribution. Bioresour. Technol. 255, 266-272. https://doi.org/10.1016/j.biortech.2018.01.100.

Zhang, J., Li, N., Dai, X., Tao, W., Jenkinson, I.R., Li, Z., 2018. Enhanced dewaterability of sludge during anaerobic digestion with thermal hydrolysis pretreatment: new insights through structure evolution. Water Res. 131, 177-185. https://doi.org/ 10.1016/j.watres.2017.12.042.

Zhang, Y., Xu, S., Cui, M., Wong, J.W.C., 2019. Effects of different thermal pretreatments on the biodegradability and bioaccessibility of sewage sludge. Waste Manag. 94, 68-76. https://doi.org/10.1016/j.wasman.2019.05.047. 